\title{
ROMANIAN
}

NEUROSURGERY

\author{
Vol. XXXIV | No. 2 June 2020
}

Intraventricular dissemination of the pilocytic astrocytomas in an adult

\author{
Vijay P. Joshi, \\ Ashwin Valsangkar, \\ Satish Nivargi, \\ Anish Dekhne, \\ Amit Agrawal
}




\section{Intraventricular dissemination of the pilocytic astrocytomas in an adult}

\author{
Vijay P. Joshi ${ }^{1}$, Ashwin Valsangkar ${ }^{1}$, Satish Nivargi ${ }^{1}$, \\ Anish Dekhne ${ }^{1}$, Amit Agrawal ${ }^{2}$ \\ 1 S. P. Institute of Neurosciences, Solapur, Maharashtra, INDIA \\ 2 Narayna Medical College Hospital, Chinthareddypalem, Nellore, \\ Andhra Pradesh, INDIA
}

\begin{abstract}
Pilocytic astrocytoma (PA) is a subset of gliomas characterized by a benign course with an excellent prognosis and rarely metastasizing or spreading along the neuraxis. We report a case of a 56-year female with intraventricular dissemination of pilocytic astrocytoma in an adult and discuss the clinical significance diagnosis and management including the peculiar pattern of dissemination of the pilocytic astrocytoma. The course of the disseminated disease may not be as good as that of patients with localized recurrence or totally resected primary disease and can vary from rapid progression to prolonged stabilization.
\end{abstract}

\section{INTRODUCTION}

Pilocytic astrocytoma (PA) is subset of gliomas characterized by a benign course with an excellent prognosis and rarely metastasizing or spreading along the neuraxis. 1-14 Dissemination of a pilocytic astrocytoma is a rare event that occurs in $2-4 \%$ of cases particularly in children. $6,8,11$ We report a case of intraventricular dissemination of pilocytic astrocytoma in an adult and discuss the clinical significance diagnosis and management including the peculiar pattern of dissemination of the pilocytic astrocytoma.

\section{CASE REPORT}

A 56-year old female patient presented with progressively increasing headache, vomiting and blurring of vision without any focal neurological deficits or seizures. Her general and systemic examination was unremarkable. Neurologically she was conscious, alert and oriented to time, place and person. Higher mental functions were normal. She had bilateral papilloedema and other cranial nerves were normal. Motor and sensory examination was normal. Her general and systemic examination was normal. The patient underwent MRI brain and it showed minimally contrast enhancing bilateral thalamic lesions, with intraventricular spread in third ventricle and the aqueduct causing obstructive hydrocephalus (Figure 1, 2 and 3). The patient underwent

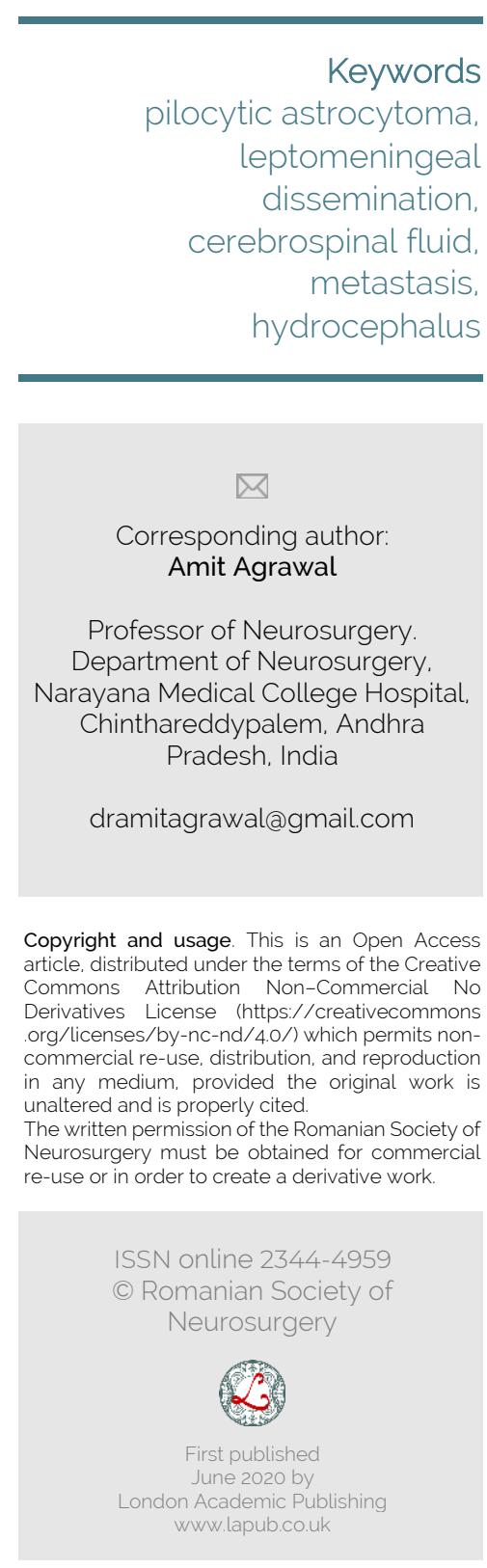


endoscopic exploration of the third ventricular lesion that could be excised as well as the lesion in the aqueduct also could be excised. Part of the lesion in the fourth ventricle was left alone as it was densely adherent to the surrounding structures. Intraoperatively external ventricular drainage was (EVD) was inserted and was kept in situ for 5 days till the CSF was acceptably clear. She later underwent right ventriculo-peritoneal shunt surgery.

Histopathological examination of the section and additional made serial deeper section showed few fragments bits of cellular neoplasm of astrocytic origin. The tumour composed admixture of compact cellular and oedematous loose-knit tissue showing scattered protoplasmic astrocytes having fairly uniform round to oval or slightly elongated nuclei with delicate - open chromaWr pattern and barely discernible cytoplasm. The fibrillary background showed few microcytfic spaces and vascular proliferation comprising few ectatic congested blood vessels Coupie of foe show doubtful Rosenthal fibers (Figure-4). No granulomas were seen. Histopathological features were consistent with 'pilocytic astrocytoma'. Section shows a tumor of moderate cellularity with cells amidst fibrillary background. Microcystic change, hyalinized vasculature were seen. No mitosis, necrosis, microvascular proliferation seen. Rosenthal fibres and eosinophilic granular bodies were seen. The tumor cells express GFAP \& P 53 (focal) and were Immunonegative for synaptophysin 8i EMA. The Mib1 labeling index was approximately 1\%. Low grade astrocytic neoplasm suggestive of pilocytic astrocytoma. In post-operative made she did well as she was conscious, with no focal neurological deficits.

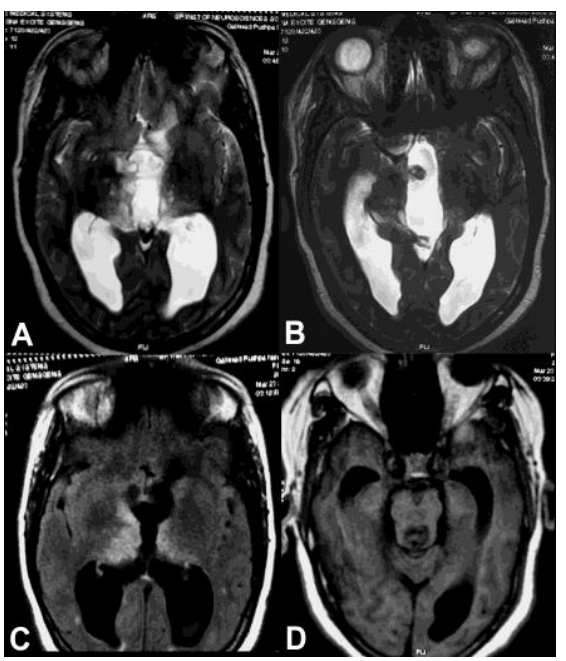

Figure 1. MRI brain T1W, T2W and Flair axial images showing bilateral thalamic tumor with blockage of

the aqueduct and associated hydrocephalus.

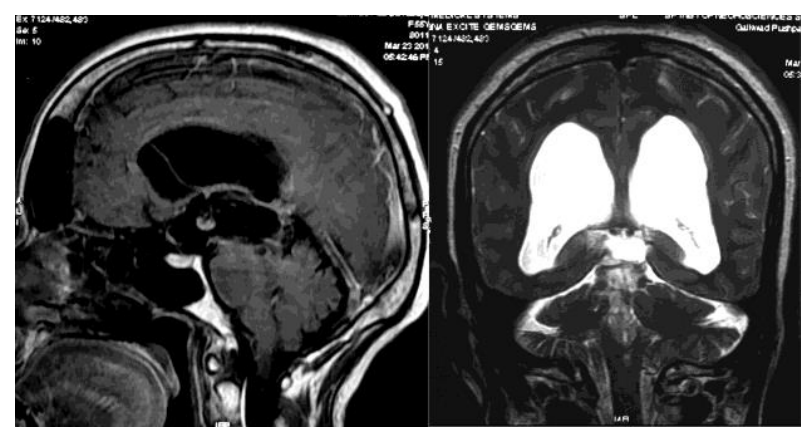

Figure 2. MRI brain T1W sagittal images and $\mathrm{T} 2 \mathrm{~W}$ coronal image showing the blockage of aqueduct by tumour.

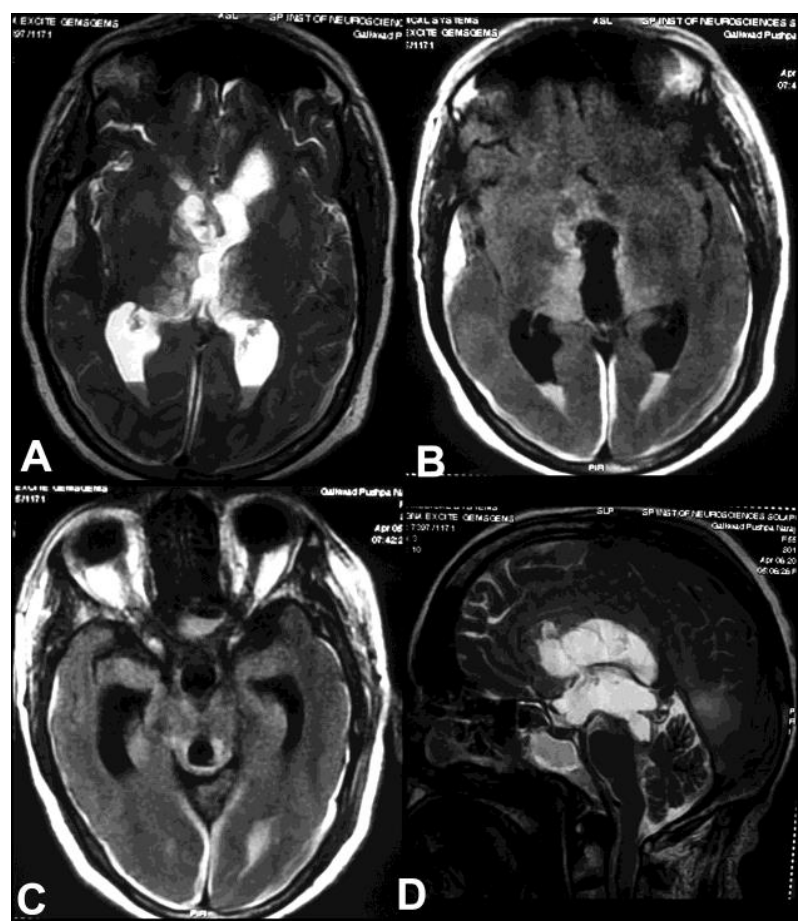

Figure 3. Post-operative MRI T2W and FLAIR axial images showing although the tumor could be removed from upper part of the aqueduct but still the lower part is closed.

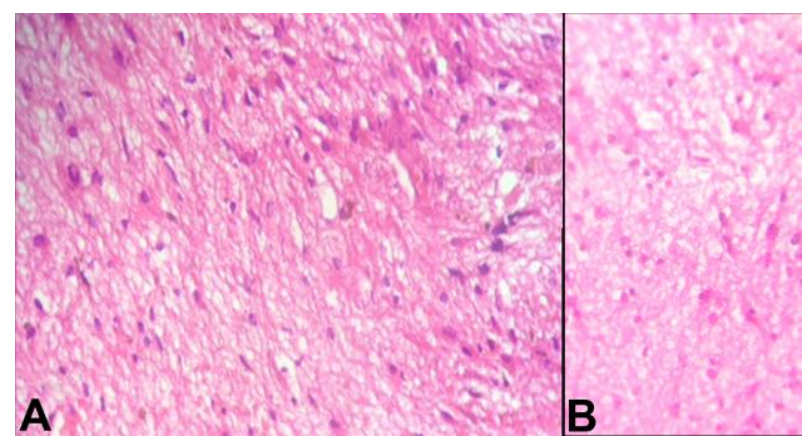

Figure 4. Histopathological examination of the section and additional made serial deeper section showed few fragments bits of cellular neoplasm of astrocytic origin. The tumour composed admixture of compact cellular and oedematous 
loose-knit tissue showing scattered protoplasmic astrocytes having fairly uniform round to oval or slightly elongated nuclei with delicate - open chromaWr pattern and barely discernible cytoplasm. The fibrillary background showed few microcytfic spaces and vascular proliferation comprising few ectatic congested blood vessels Coupie of foe show Rosenthal fibers.

\section{DISCUSSION}

Dissemination of primary central nervous system neoplasms along the neuraxis is commonly associated with high grade lesions i.e. medulloblastoma, germ cell tumors and malign glial tumors. ${ }^{1-5,11,15-18}$ Dissemination of low-grade gliomas has been documented only in few cases. 1-14, 19 Usually the site of dissemination is spinal $1,6,8,11,16,19$ 23 but in rare cases it can be intraventricular metastasis leading to hydrocephalus. ${ }^{21}$ Clinically it can occur after a long postoperative period or may be the first sign of disease or of relapse. $1,6,8,11,16,19-25$ The clinical presentation ranges from asymptomatic cases to hydrocephalus, meningismus, worsening of focal deficits, new onset of neurological deficits and onset of seizures. ${ }^{8}, 11,19,24$ The tumour spread in these patients is via the CSF and it is accepted that low grade astrocytomas in proximity to ventricles or CSF cisterns are more likely to spread than deeply located tumors. ${ }^{21,26,27}$ Several mechanisms have been hypothesized to explain the spread of intracranial tumors by CSF pathways including malignant transformation, cellular anaplasia, surgical manipulation, natural history, multiplicity and presence of cell adhesion molecules (CD44 adhesion molecule as it may play a role in astrocytic invasion and adhesion). ${ }^{7,28}$ It has been suggested that the tumor mass located in the floor of the third ventricle may breach the ependyma, invading the ventricular cavity and thus resulting in to ependymal or leptomeningeal seeding. 2,3, 5, 8,9

Pilocytic astrocytoma is a benign tumor that corresponds to histological Grade I 13, 29-31 and associated with 20-year survival rates of greater than $90 \%$ in patients who undergo total excision of the lesion. ${ }^{8}, 13,29,30$ Presently there is not much known about the optimum treatment and course of disseminated low-grade astrocytomas. 1, 2, 14, 16, 32 Probably hydrocephalus, biopsy and partial resection may also be additional favorable factors, although this remains unproven. ${ }^{8,14}$ In has been suggested that the total resection must be performed as often as possible and no adjuvant therapy should be carried out for low grade gliomas,
13, 14 however the treatment of the disseminated tumor, remains controversial. ${ }^{14,20,25}$ The course of the disseminated disease may not be as good as that of patients with localized recurrence or totally resected primary disease and can vary from rapid progression to prolonged stabilization. ${ }^{1,2,14,16,25,32 ~ 11, ~}$ 20,21

\section{REFERENCES}

1. Civitello LA, Packer RJ, Rorke LB, Siegel K, Sutton LN, Schut L. Leptomeningeal dissemination of low-grade gliomas in childhood. Neurology 1988;38:562-566.

2. Gajjar A, Bhargava R, Jenkins JJ, et al. Low-grade astrocytoma with neuraxis dissemination at diagnosis. Journal of neurosurgery 1995;83:67-71.

3. Kellie SJ, Kovnar EH, Kun LE, et al. Neuraxis dissemination in pediatric brain tumors. Response to preirradiation chemotherapy. Cancer 1992;69:1061-1066.

4. Packer RJ, Siegel KR, Sutton LN, Litmann P, Bruce DA, Schut L. Leptomeningeal dissemination of primary central nervous system tumors of childhood. Annals of neurology 1985;18:217-221.

5. Ushio Y, Arita N, Hayakawa T, et al. Leptomeningeal dissemination of primary brain tumors in children: clinical and experimental studies. Progress in experimental tumor research 1987;30:194-205.

6. McCowage G, Tien R, McLendon R, et al. Successful treatment of childhood pilocytic astrocytomas metastatic to the leptomeninges with high-dose Cyclophosphamide. Medical and Pediatric Oncology 1996;27:32-39.

7. Morikawa M, Tamaki N, Kokunai T, et al. Cerebellar pilocytic astrocytoma with leptomeningeal dissemination: case report. Surgical neurology 1997:48:49-51; discussion 51.

8. Mamelak AN, Prados MD, Obana WG, Cogen PH, Edwards MS. Treatment options and prognosis for multicentric juvenile pilocytic astrocytoma. Journal of neurosurgery 1994;81:24-30.

9. 9.Garcia DM, Fulling KH. Juvenile pilocytic astrocytoma of the cerebrum in adults. A distinctive neoplasm with favorable prognosis. Journal of neurosurgery 1985;63:382-386.

10. Gjerris F, Klinken L. Long-term prognosis in children with benign cerebellar astrocytoma. Journal of neurosurgery 1978;49:179-184.

11. Shapiro K, Shulman K. Spinal cord seeding from cerebellar astrocytomas. Child's brain 1976;2:177-186.

12. Haddad SF, Menezes AH, Bell WE, Godersky JC, Afifi AK, Bale JF. Brain tumors occurring before 1 year of age: a retrospective reviews of 22 cases in an 11-year period (1977-1987). Neurosurgery 1991;29:8-13.

13. Wallner KE, Gonzales MF, Edwards MS, Wara WM, Sheline GE. Treatment results of juvenile pilocytic astrocytoma. Journal of neurosurgery 1988;69:171-176. 
14. Figueiredo EG, Matushita H, Machado AGG, Plese JPP, Rosemberg S, Marino R. Leptomeningeal dissemination of pilocytic astrocytoma at diagnosis in childhood: two cases report. Arquivos de neuro-psiquiatria 2003;61:842847.

15. Pezeshkpour GH, Henry JM, Armbrustmacher VW. Spinal metastases. A rare mode of presentation of brain tumors. Cancer 1984;54:353-356.

16. Mishima $\mathrm{K}$, Nakamura $\mathrm{M}$, Nakamura $\mathrm{H}$, Nakamura $\mathrm{O}$, Funata N, Shitara N. Leptomeningeal dissemination of cerebellar pilocytic astrocytoma. Case report. Journal of neurosurgery 1992;77:788-791.

17. Arseni C, Horvath L, Carp N, Constantinescu A, Ciurea V. Spinal dissemination following operation on cerebral oligodendroglioma. Acta neurochirurgica 1977;37:125137.

18. Bell WO, Packer RJ, Seigel KR, et al. Leptomeningeal spread of intramedullary spinal cord tumors. Report of three cases. Journal of neurosurgery 1988;69:295-300.

19. Pollack IF, Hurtt M, Pang D, Albright AL. Dissemination of low grade intracranial astrocytomas in children. Cancer 1994;73:2869-2878.

20. Auer RN, Rice GP, Hinton GG, Amacher AL, Gilbert JJ. Cerebellar astrocytoma with benign histology and malignant clinical course. Case report. Journal of neurosurgery 1981;54:128-132.

21. Jamjoom AB, Jamjoom ZA, al-Rayess $M$. Intraventricular and leptomeningeal dissemination of a pilocytic cerebellar astrocytoma in a child with a ventriculoperitoneal shunt: case report. British journal of neurosurgery 1998;12:56-58.

22. Tamura M, Zama A, Kurihara $\mathrm{H}$, et al. Management of recurrent pilocytic astrocytoma with leptomeningeal dissemination in childhood. Child's nervous system : ChNS : official journal of the International Society for Pediatric Neurosurgery 1998;14:617-622.
23. Versari P, Talamonti G, D'Aliberti G, Fontana R, Colombo $\mathrm{N}$, Casadei G. Leptomeningeal dissemination of juvenile pilocytic astrocytoma: case report. Surgical neurology 1994;41:318-321.

24. Patt S, Haberland N, Graupner H, Schreiber D, Kalff R. May 1999--16 year old male with an unexpected MRI finding. Brain pathology (Zurich, Switzerland) 1999;9:743744.

25. Kanda M, Tanaka H, Shinoda S, Masuzawa T. Leptomeningeal dissemination of pilocytic astrocytoma via hematoma in a child. Case report. Neurosurgical focus 2002;13:ECP2.

26. Prados M, Mamelak AN. Metastasizing low grade gliomas in children. Redefining an old disease. Cancer 1994;73:2671-2673.

27. Obana WG, Cogen PH, Davis RL, Edwards MS. Metastatic juvenile pilocytic astrocytoma. Case report. Journal of neurosurgery 1991;75:972-975.

28. 28. Cooper DL, Dougherty GJ. To metastasize or not? Selection of CD44 splice sites. Nature medicine 1995;1:635-637.

29. Garcia DM, Latifi HR, Simpson JR, Picker S. Astrocytomas of the cerebellum in children. Journal of neurosurgery 1989;71:661-664.

30. Geissinger JD. Astrocytomas of the cerebellum in children. Long-term study. Archives of neurology 1971;24:125-135.

31. Kleihues P, Cavenee W. Tumours of the nervous system: pathology and genetics. World Health Organization Classification of Tumours IARC Press, Lyon 2000:198-203.

32. Packer RJ, Lange B, Ater J, et al. Carboplatin and vincristine for recurrent and newly diagnosed low-grade gliomas of childhood. Journal of clinical oncology : official journal of the American Society of Clinical Oncology 1993;11:850-856. 